\title{
Empyema in spinal canal in thoracic region, abscesses in paravertebral space, spondylitis: in clinical course of zoonosis Erysipelothrix rhusiopathiae
}

\author{
Jarosław Andrychowski • Piotr Jasielski • \\ Tomasz Netczuk $\cdot$ Zbigniew Czernicki
}

Received: 6 December 2009/Revised: 30 October 2011/ Accepted: 18 March 2012/Published online: 17 April 2012

(C) The Author(s) 2012. This article is published with open access at Springerlink.com

\begin{abstract}
Objectives Erysipelas is an animal disease caused by Grampositive bacteria Erysipelothrix rhusiopathiae. Among the domestic animals, domestic pig (Sus scrofa f. domestica) suffers most frequently from the disease in human environment. This is a typical animal-borne disease observed mainly in occupational groups employed in agriculture, farming (of animals and birds), fishing and manufacturing industry.

Methods We are presenting the clinical course of infection (E. rhusiopathiae) and discuss clinical forms. E. rhusiopathiae in humans may have the following clinical course: mild form of skin infection diagnosed as local erythema (erysipeloid), disseminated form of skin infection and the most serious form of infection of systemic course (endocarditis and sepsis). Mild skin infection and local erythema are the most common forms. Very rare case of animal-borne infection course has been presented in which after initial phase the disease was generalised to the abscesses formation in paravertebral space, spondylitis and empyema formation in spinal canal. In the presented clinical case, the patient was suffering from diabetes. It was probably an additional risk factor of the disease generalisation. Patient underwent drainage of empyema in spinal canal, after which his neurological status gradually improved. Antibiotic therapy was implemented and continued for 8 weeks. Such course of erysipelas was not previously described in the literature.
\end{abstract}

J. Andrychowski $(\bowtie) \cdot$ P. Jasielski $\cdot$ T. Netczuk $\cdot$ Z. Czernicki Department of Neurosurgery, Mossakowski Medical Research Centre, Polish Academy of Sciences, Bielanski Hospital, Ceglowska Str 80, 01-809 Warsaw, Poland

e-mail: j.andrychowski@wp.pl

J. Andrychowski · T. Netczuk · Z. Czernicki Medical University of Warsaw, Bielanski Hospital, Cegłowska Str 80, 01-809 Warsaw, Poland
Results After therapy neurological status was improved. In follow MRI control exam empyema and spondylitis was successfully eliminated.

Conclusions Various complications of the disease, such as endocarditis and heart valves disturbances, are well known and are the most severe complications of the generalised infection. Proper targeted and long-term antibiotic therapy is crucial.

Keywords Zoonosis - Erysipelothrix rhusiopathiae . Abscesses in paravertebral space $\cdot$ Spondylitis

\section{Introduction}

Erysipelas is an animal disease caused by Gram-positive bacteria Erysipelothrix rhusiopathiae. Among the domestic animals, domestic pig (Sus scrofa f. domestica) suffers most frequently from the disease in human environment. This is a typical animal-borne disease observed mainly in occupational groups employed in agriculture, farming (of animals and birds), fishing and manufacturing industry. Moreover, the people employed by animal waste segregation and utilisation companies belong to the risk group.

Erysipelas infection is a result of contact with infected animal, animal-borne contamination, animal-derived products or wastes.

Infection in humans may have the following clinical course: mild form of skin infection diagnosed as erythema (erysipeloid), disseminated form of skin infection and the most serious form of infection of systemic course (endocarditis and sepsis). Mild skin process and local erythema are the most common forms of infection. Despite sanitary control and advanced manufacturing industry, erysipeloid concerns specific occupational groups and is a serious 
economic problem in cases of E. rhusiopathie carrying by animals.

Usually observed and diagnosed dermatologic forms of disease are treated easily. More serious cardiological complications being a consequence of more serious forms of disease are rarely observed.

Very rare case of animal-borne (zoonosis) infection course in disseminated form of spinal canal empyema, perivertebral abscess and spondylitis was presented. In the presented case, no evidenced changes in heart muscle and circulatory system were confirmed clinically and by laboratory test results.

\section{Case report}

62-year-old male patient working as a farmer and suffering from type 2 diabetes was admitted to the Neurology Department due to paraplegia of lower extremities, sphincters disturbances and sensation disturbances from the level of Th6. During the last 14 days preceding hospitalisation he moved with significant difficulty and reported weakness of the lower extremities. 4 days prior to admission he spent most of his time mainly in bed and suffered from paraplegia of lower extremities. After admission to the Neurology Department, initial diagnostics showed the presence of destructive changes within vertebral bodies, arches and spinous processes in the thoracic segment (Th5Th6).

CT scans revealed destruction of the thoracic vertebras, infiltration changes in paravertebral soft tissues and pathological mass in the spinal canal. Initial diagnosis included infiltrative malignant tumour of the vertebral column. Consulting neurosurgeon recommended MRI examination. Examination revealed the presence of changes suggesting inflammatory process of the thoracic spine Th5-Th6, inflammatory changes within intervertebral discs and vertebral bodies and changes inside the spinal canal suggesting fluid mass empyema compressing the spinal cord (Figs. 1, 2).

Additional information collected from the patient and his family revealed that the patient suffered from the zoonosis, erysipeloid, 2 months priori to admission and was treated. Infection occurred after skin cut on the right leg with the fragment of the pig bone. Patient observed the presence of skin inflammatory process; subsequently, the process spread in the form of phlegmon of the right leg integuments. Patient was initially treated in the Department of Surgery and referred to the Orthopaedic Clinic due to skin phlegmon. Bacteriological tests revealed E. rhusiopathiae. Patient underwent drainage of the subcutaneous tissues. Targeted antibiotic therapy was implemented and continued for about 3 weeks after operation. As the family

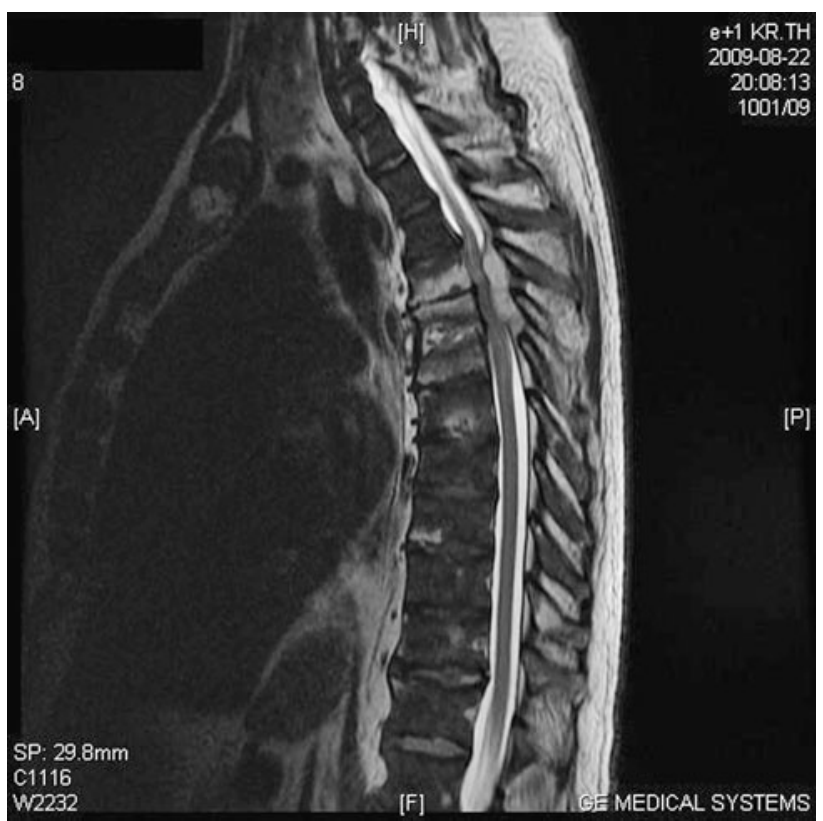

Fig. 1 MRI examination before operation. Inflammatory process in the vertebrae and disc. Disc space narrowing and abscess in spinal canal

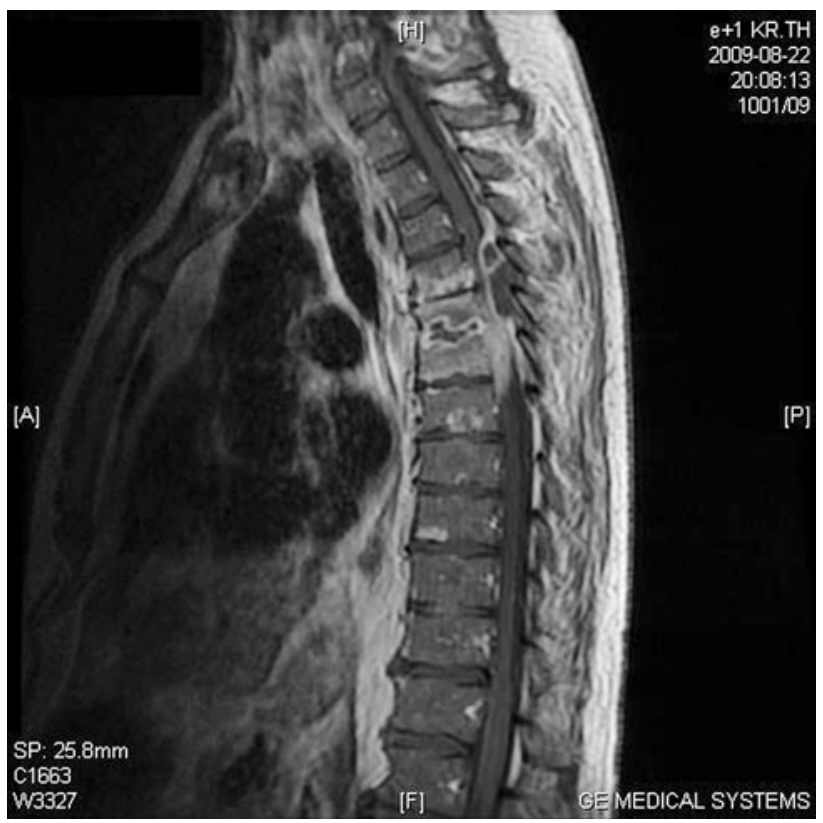

Fig. 2 MRI examination before operation with contrast. Spinal cord compression

reported, patient reported back pain localised in the thoracic segment in the midline; nevertheless $\mathrm{X}$-ray imaging of the spine was not performed, any local changes were observed within the paravertebral and superficial tissues. During admission and hospitalisation in the Neurosurgery Department, patient was suffered from glycaemia instability. As the normal levels of glycaemia were obtained, 
patient underwent operation. With regard to the process including distant vertebras and the risk of instability, double-level decompressing hemilaminectomy on the Th5Th6 level was performed. Pus cistern of paravertebral localisation was found immediately after the incision of fascia lata. Infiltration of vertebral arches, vertebral joints and spinous processes was also observed. After flavectomy, epidural empyema was observed inside the spinal canal. Flow drainage of the operation field was performed for 5 days. In the post-operational period, cephalosporin was intravenously administered. Cultures and fragments of excised tissues were taken for histological examination. Local culture samples were collected from the wound during chronic infection as well as blood culture samples at the stage of systemic symptoms. Erysipelothrix rhusiopathiae were isolated. The patient was administered antibiotics based on culture outcomes and antibiogram. After spinal surgery, no pathological growth was observed in the collected samples-negative cultures.

On the 6th day after operation, control imagining (MRI) was performed which revealed evacuation of the empyema cavity.

Postoperative MRI examination revealed state after the hemilaminectomy and empyema drainage. The presence of inflammatory changes mainly in the Th5-Th6 segment in form of oedema of vertebral bodies, wedge-shaped vertebral bodies and uneven shape of intervertebral disc, spinal cord oedema, suspicion of inflammation, remnants of the empyema cavity in the spinal canal was observed.
Clinically, unchanged neurological state was observed. Once the wound was healed, the patient was transferred to the Department of Infectious and Animal-borne Diseases and Rehabilitation with the brace (Fig. 3).

The clinical assessment after 16 months post operation revealed paraparesis of the lower extremities in neurological examination but the motor deficit was improved during this time. Patient was moving with a wheelchair.

A follow-up MRI scan was performed within 16 months postoperatively. There was visible; status post Th5-Th6 hemi laminectomy, status post spondylodiscitis involving Th4, Th5, Th6 and Th7 vertebrae. Bone remodelling visible in Th5 and Th6 behind the damaged intervertebral disc as well as postinflammatory lesions within the Th4 and $\mathrm{Th} 7$ vertebrae. Spinal cord showing lesions at the level of Th4Th5 (Figs. 4, 5).

\section{Difficult zoonosis in the last time. Etiology and social problem}

The definition of zoonosis was given in 1958 by WHO. Virchow was the first one to coin the term related to zoonosis as the problem in the human clinic in 1985, whereas as a veterinarian term it was introduced by W. Probstmayer in 1863 .

Zoonoses are widespread all over the world with reference to the infection transmission ca. 200 types have been identified. The occurrence of zoonoses, exposition to the

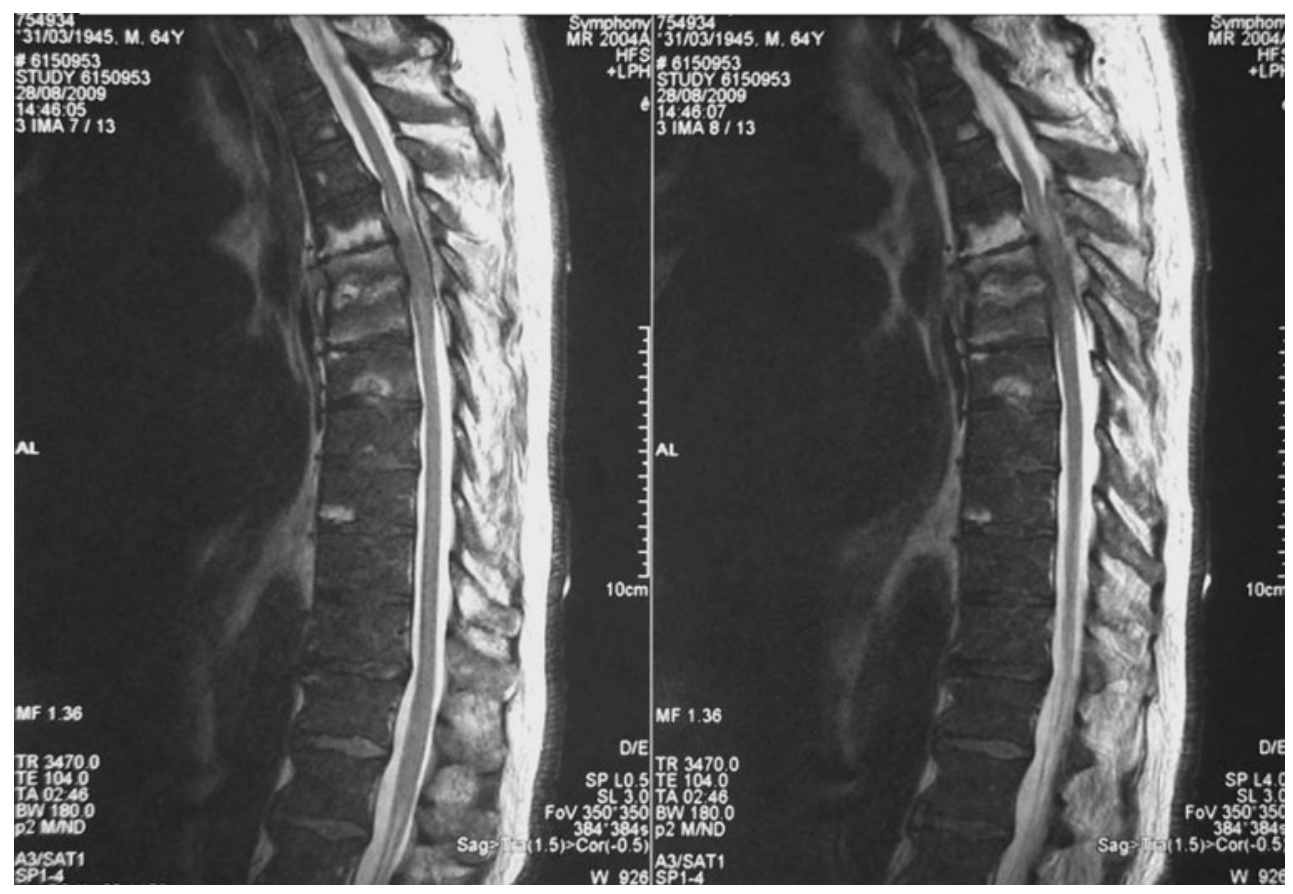

Fig. 3 MRI postoperative control examination 6 days after operation. Decompression of spinal canal. Spondylodiscitis. Lesion of the spinal cord in postoperative level 


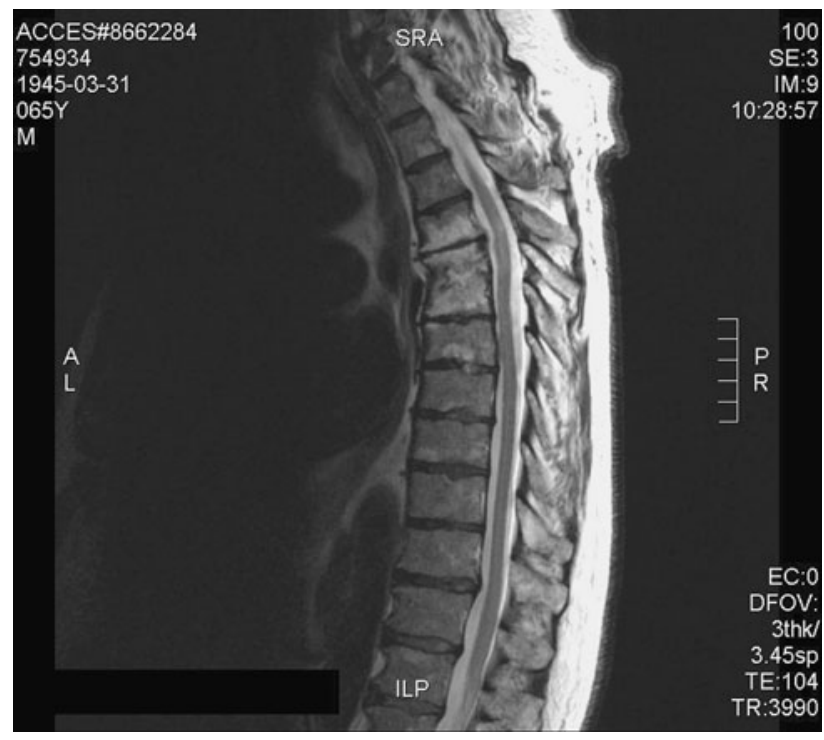

Fig. 4 The follow-up MRI examination after 14 months post operation. Bone remodelling visible in Th5 and Th6 behind the damaged intervertebral disc as well as postinflammatory lesions within the Th4 and Th7 vertebrae. Spinal cord showing lesions at the level of Th4 Th5

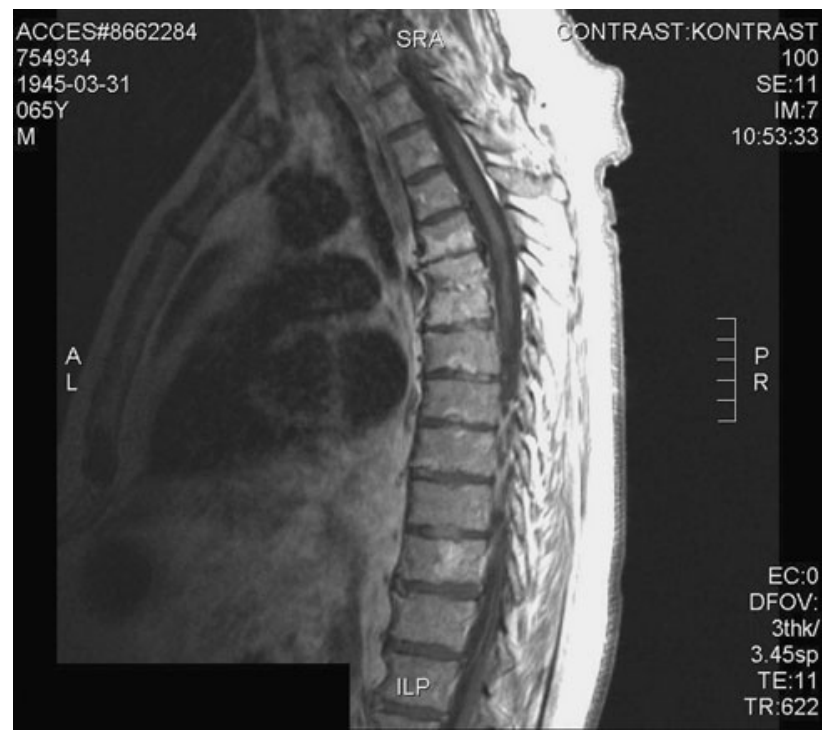

Fig. 5 The follow-up MRI examination with contrast after 14 months post operation. Bone remodelling visible in Th5 and Th6 behind the damaged intervertebral disc as well as postinflammatory lesions within the Th4 and Th7 vertebrae. Spinal cord showing lesions at the level of Th4-Th5

transmission factors refers to the population of both developing and developed countries and is a civilizational phenomenon. The prevention of possible infection paths of zoonotic infections is related to the civilizational level of a given country and its society. It is also related to an institution of veterinarian supervision. Lack of effective veterinarian supervision may result in the spread of zoonoses. Highly industrialised countries are equipped with a whole arsenal of services and resources allowing for effective prevention. However, it does not mean that zoonoses do not occur in the societies enjoying economic prosperity. They may occur in persons employed in agriculture, fishing and animal processing. They are related to groups of professional risk and persons disregarding supervisory procedures and educationally unaware. They may occur in pet breeders and, what is most interesting, they are also related to various culinary habits of various countries and cultures.

Prions In recent decades, diseases transmitted by prions have become a real challenge to medicine due to necessary mechanisms of prophylactics and little effectiveness of their treatment. Creutzfeldt-Jakob Disease (CJD) is a transmissible spongiform encephalopathy (TSE). Cases of bovine spongiform encephalopathy (BSE) have been also detected. CJD occurs in many etiological subtypes. Sporadic CJD-sCJD, genetic forms of human TSE (sTSE)genetic forms of diseases like Gerstmann-StausslerScheinker-Syndrome, fatal familial insomnia. The iatrogenic form of these diseases iCJD is associated with the transmission of the infection among humans by implants or preparations containing hormone of human origin. The disease transmission during neurosurgical procedures is also possible, which has been documented in the literature. One of subtypes of spongiform encephalopathy in humans, subtype variant Creutzfeldt-Jakob Disease (vCJD), is evidently related to bovine spongiform encephalopathy (BSE) transmission onto humans $[9,13,16,20,23,33,39,43$, 44].

The problem refers to developed countries. There are distinct suggestions that other types of spongiform encephalopathy may also be zoonosis, e.g. sCJD. In order to prevent the transmission of epidemiological factors in the recent decades, a monitoring system of animal breeding and epidemiological supervision has been developed in detail by certain internal regulations as well as on European Union level. It is also considered that presently recognisable cases of CJD in the world, due to the long incubation period of the diseases, may also be the consequence of the exposition to the pathogenic-zoonotic factor prior to the introduction of effective diagnostic methods of infections in animals.

SARS The another zoonosis known in recent years. Viral zoonoses are widespread, in recent years, SARS (severe acute respiratory syndrome) has been a large problem in Far East Asia. In the epidemiological aspect, the reason for SARS infection is coronaviridae, coming from a big Chinese cat so-called civet-a culinary delicacy from the region of Kanton. This disease afflicts the respiratory system, usually takes the form of a mild infection with a fever, 
however, severe cases of life-threatening pneumonia may occur [2, 7, 24, 30, 36].

Avian influenza (bird flu) recently, world news has been dominated by data related to the form of influenza of zoonotic origin. The epidemiology of the phenomenon has been related to the areas of Far East Asia, actions aimed at the counteraction of the epidemic spread consisting in the mass liquidation of chicken farms constituting a natural reservoir of the epidemic have represented a particularly drastic view. The infections of avian influenza are caused by A H5N1 virus, whose reservoir in nature is wild fowl, the virus is transmitted easily to poultry and shows very high pathogenicity. On poultry farms it undergoes numerous modifications and can be pathogenic to humans. The virus is widespread in the world, it is found in many organisms, also in humans. In certain situations, it becomes pathogenic. Poultry farms, particularly in Asian areas, are thought to be the source of modification of avian influenza virus gaining the properties of a pathogen that is dangerous to human organisms. In such situations, the monitoring of poultry farming as well as quick identification of an infection in humans is of extreme importance. Even slight number of diagnosed infections caused by avian influenza in humans, sometimes unfortunately of very severe course, constitutes particular information about the virus pathogenicity and consequently leads to the decision of liquidating a given reservoir [11, 21, 26, 29, 47].

Swine influenza (pig flu) has been initially so-called due to the type of virus isolated in swine organism and concurrently found in humans. Initially such name was pushed by the World Health Organisation. Falling ill is caused by the strain of virus A H1N1v/additionally marked with (v) to differentiate it from the types of influenza virus causing seasonal infections. This virus undergoes constant modifications. Infections in humans can be caused by the influenza virus that infects pigs and so far there have been such cases among persons having contact with animals, particularly among farm workers. However, recent infections found in the human clinic are mutated forms of viral infections where the virus contains elements of both human and avian influenza genome. In such situation, a pig farm can be the reservoir where a certain virus may undergo mutation and become dangerous to human and the infection course may be severe.

The above-mentioned viral diseases have been particularly noticeable in recent decades as diseases of civilization featured in mass media and also have constituted a high degree risk [1, 18, 32, 37, 38, 40].

In the human clinic also diseases of bacterial origin are present, to mention just the few most frequent ones: cat scratch disease, plague, anthrax, Lyme disease, brucellosis, tuberculosis, erysipeloid, salmonellosis, leptospirosesWeil's disease, malaria, Stuttgart disease and listeriosis.
There are also parasitical diseases, of which the most frequent in developed countries is trichinosis, caused when humans are infected with by eating infected meat. The reasons of zoonoses include also protozoa and helminths.

\section{Discussion}

Spinal infections are painful for patients and frustrating for doctors, it can be pyogenic (bacterial) granulomatous (tuberculosis or fungal) and after parasitic contamination. We divide pyogenic spinal infection from the clinical point of view to spondylodiscitis, septic discitis, vertebral osteomyelitis and epidural abscess. The most frequently isolated pathogen is Staphylococcus aureus [3, 6, 15, 25, 28].

Presented severe clinical course of zoonosis (erysipelasE. rhusiopathiae) in form infection of vertebral column and spinal canal with accompanying severe neurological deficit is extremely rare. Probably the diabetes as additional risk factor caused generalisation of the skin infection and blood-derived abscess formation.

Human-acquired infection in majority of cases is limited to the inflammatory (skin process)—erythema (erysipeloid) of definite limitation. Diffused skin changes are rare, systematic infections are the rarest-endocarditis, which may cause permanent changes on the heart valves. Sometimes insignificant scratches, i.e. during the work, and erysipeloid, a disease of specific occupational groups, may in consequence lead to the disease generalisation as sepsis [4, $5,8,14,19]$. Cases of glomerulonephritis and meningitis in the course of E. rhusiopathiae infection are described [22, $27,45]$. Intra-articular infections in peri-operational period after endoscopy of the knee joint are described [42, 46].

Cardiological complications may result in infectiontypical predilection to changes formation on the left heart structures, especially in aortic valve. Endocarditis in result of E. rhusiopathiae infection is burdened with high mortality about 33-38\% of cases compared to endocarditis of different aetiologies, mycotic aneurysms, valve damages, heart muscle empyemas are another complications of the infection. So far documented course with multiple paravertebral abscess formation, empyema formation in the spinal canal and inflammatory changes within the vertebral column was not fund in review of literature by the authors. The infection factor (E. rhusiopathiae) is a bacterium, gram-positive popular rod in land or water environment, occurring as pathogen, commensal or saprophyte in domestic and wild animals. A bacterium is also observed in fish and sea mammals. In animals, the infection may have character of severe sepsis, subacute course-the form of multifocal skin changes and chronic-with accompanying endocarditis and arthritis [5, 12, 17, 19, 31, 35]. Domestic pig is the most important reservoir of bacterium $E$. 
rhusiopathiae in the environment; the infecting agent is released from the infected animals by faeces, sweat and excreted mucous which pollute food and water. Aspect of carrying in about $20-40 \%$ of healthy animal population, as the potential source of the infection transmission is stressed.

Erysipelothrix rhusiopathiae as the epidemiologic problem and exposition of occupational groups on the infectious factor are discussed in medical and veterinary literature. Occurrence of erysipelas infection became reduced due to safe technological processes in animals processing, specific safety procedures and, as a consequence, limitation of exposition of occupational groups on the infection $[5,8,48,49]$.

Human becomes infected by direct contact with animalderived pollutions, infected animals, and via animalderived products or remains of the animal bodies without veterinary supervision.

Generalised process with endocarditis formation is the most dangerous form of infection for the human being.

Clinical course in human depends most of all on proper diagnosis of initial phase of disease and implementation of targeted antibiotic therapy to prevent severe forms of infection. Despite effective therapy of skin manifestation of the disease, recurrences of disease and sepsis occurred. Bacterium is sensitive to majority of penicillins, cephalosporins and lincosamides. The resistance is presented towards aminoglycosides and vancomycin. Proper therapy of skin changes is of crucial importance-management in the initial phase of disease, so that the antibiotic therapy is proper and the insignificant scratch did not become an exit point of generalised infection [5, 10, 34, 41]. For severe forms of infection, sepsis and endocarditis, recommended antibiotic therapy should be administered by $4-6$ weeks or longer depending on the form of the course and localisation of infection, i.e. in complicated purulent knee endoscopic surgery presented in the case report antibiotic therapy was administered for 16 weeks [19, 42, 45, 46].

Due to the way of transmission, environmental factors, potential bacteria carriers in presumed healthy animal population, erysipelas remains a disease of specific occupational groups that contact with animals and their tissues.

In animal-borne disease, the elimination of bacteria carriers is of crucial importance. It can be done with special safety procedures and local disinfection, as mentioned in publications, gave an effect in morbidity decrease. Sanitary supervision is important in morbidity reduction; however, the elimination of accidental injury of integuments is very difficult. Proper diagnosis and therapy prevent spreading of the infection.

In the presented case, two factors, which could be responsible for such course, occurred; diabetes which modifies the course of infection and probably too short period of antibiotic therapy only 3 weeks of the skin and subcutaneous process. Indications for long-term antibiotic therapy exist in case of complicated infections.

\section{Conclusions}

1. Unusual, complicated courses caused by E. rhusiopathiae in patients with diabetes require prolonged antibiotic therapy.

2. Proper diagnosis and therapy of local skin changes are crucial.

3. Very rare clinical course of erysipelas in form of spondylitis, paravertebral abscesses and empyema in spinal canal was presented.

Conflict of interest None of the authors has any potential conflict of interest.

Open Access This article is distributed under the terms of the Creative Commons Attribution License which permits any use, distribution, and reproduction in any medium, provided the original author(s) and the source are credited.

\section{References}

1. Al-Muharrmi Z (2010) Understanding the Influenza A H1N1 2009 Pandemic. Sultan Qaboos Univ Med J 10(2):187-195 (Epub 2010 Jul 19)

2. Anderson LJ, Tong S (2010) Update on SARS research and other possibly zoonotic coronaviruses. Int $\mathrm{J}$ Antimicrob Agents 36(Suppl 1):S21-S25 (Epub Aug 30 Review)

3. Asamoto S, Doi H, Kobayashi N, et al (2005) Spondylodiscitis: diagnosis and treatment. Surg Neurol 64:103-108 (discussion 108)

4. Artz AL, Szabo S, Zabel LT, Hoffmeister HM (2001) Aortic valve endocarditis with paravalvilar abscesses caused by Erysipelothrix rhusiopathiae. Eur J Clin Microbiol Infect Disease 20:587-588

5. Brooke J, Riley T (1999) Erysipelothrix rhusiopathiae: bacteriology, epidemiology and clinical manifestations of an occupational pathogen. J Med Microbiol 48:789-799

6. Butler JS, Shelly MJ, Timlin M, Powderly WG, O Byrne JM (2006) Nontuberculous pyogenic spinal infections in adults a 12 year experience from a tertiary referral center. Spine (Phila P 1976) 31:2695-2700

7. Cleri DJ, Ricketti AJ, Vernaleo JR (2010) Severe acute respiratory syndrome (SARS). Infect Dis Clin North Am 24(1):175-202

8. Cooke LJ, Bowles KM, Craig JI, Sule O (2006) Occupational injury in a fishmonger with a macular rash, hepatosplenomegaly and pancytopenia. J Clin Pathol 59:993-994

9. Elam G, Oakley K, Connor N, Hewitt P, Ward HJ, Zaman SM, Chow Y, Marteau TM (2011) Impact of being placed at risk of creutzfeldt-jakob disease: a qualitative study of blood donors to variant CJD cases and patients potentially surgically exposed to CJD. Neuroepidemiology 36(4):274-281 (Epub ahead of print)

10. Fidalgo SG, Longbottom CJ, Rjley TV (2002) Susceptibility of Erysipelothrix rhusiopathiae to antimicrobial agents and home disinfectants. Pathology 34(5):462-465 
11. Fiebig L, Soyka J, Buda S, Buchholz U, Dehnert M, Haas W (2011) Avian influenza A(H5N1) in humans: new insights from a line list of World Health Organization confirmed cases, September 2006 to August 2010. Euro Surveill 16(32) (pii:19941)

12. Fidalgo SG, Riley TV (2004) Detection of Erysipelothrix rhusiopathiae in clinical and environmental samples. Methods Mol Biol 268:199-205

13. Garske T, Ghani AC (2010) Uncertainty in the tail of the variant Creutzfeldt-Jakob disease epidemic in the UK. PLoS One 5(12):e15626

14. Grabowski M, Cybulski M, Szostek J, Stepińska J (2004) Infective endocarditis caused by Erysipelothrix rhusiopathiae: case report. Kardiol Pol 60(2):142-144

15. Hadjipavlou AG, Mader JT, Necessary JT, Muffoletto AJ (2000) Hematogenous pyogenic spinal infections and their surgical management. Spine (Phila Pa 1976) 25:1668-1679

16. Hervé R, Secker TJ, Keevil CW (2010) Current risk of iatrogenic Creutzfeld-Jakob disease in the UK: efficacy of available cleaning chemistries and reusability of neurosurgical instruments. J Hosp Infect 75(4):309-313 (Epub 2010 May 6)

17. Hill DC, Ghassemian JN (1997) Erysipelothrix rhusiopathiae endocarditis clinical features of occupational disease. South Med J 90:1147-1148

18. Hilton S, Hunt K (2011) UK newspapers' representations of the 2009-10 outbreak of swine flu: one health scare not over-hyped by the media? J Epidemiol Community Health 65(10):941-946 (Epub 2010 Dec 3)

19. Hjetland R, Søgnen E, Våge V (1995) Erysipelothrix rhusiopathiae a cause of erysipeloid and endocarditis. Tidsskr Nor Laegeforen 115(22):2780-2782

20. Holman RC, Belay ED, Christensen KY, Maddox RA, Minino AM, Folkema AM, Haberling DL, Hammett TA, Kochanek KD, Sejvar JJ, Schonberger LB (2010) Human prion diseases in the United States. PLoS One 5(1):e8521

21. Kandeel A, Manoncourt S, Abd el Kareem E, Mohamed Ahmed AN, El-Refaie S, Essmat H, Tjaden J, de Mattos CC, Earhart KC, Marfin AA, El-Sayed N (2010) Zoonotic transmission of avian influenza virus (H5N1), Egypt, 2006-2009. Emerg Infect Dis 16(7):1101-1107

22. Kim RS, Kwon JM, Lee HJ, Lee YN (2007) Chronic meningitis caused by Erysipelothrix rhusiopathiae. J Med Microbiol 56:1405-1406

23. Knight R (2010) The risk of transmitting prion disease by blood or plasma products. Transfus Apher Sci 43(3):387-391 (Epub 2010 Nov 11)

24. Leung GM, Ho LM, Lam TH, Hedley AJ (2009) Epidemiology of SARS in the 2003 Hong Kong epidemic. Hong Kong Med J 15(Suppl 9):12-16

25. Lew DP, Waldvogel FA (2004) Osteomyelitis. Lancet 364:369-379

26. Li XH, Tian HD, Heiner M, Li DM (2011) Global occurrence and spread of highly pathogenic avian influenza virus of the subtype H5N1. Avian Dis 55(1):21-28

27. Luca MC, Dorneanu O, Sabadîş L, Dorobăţ C, Fîntînaru R, Luca V (2005) Erysipelothrix rhusiopathiae-rare etiology of persistent febrile syndrome. Rev Med Chir Soc Med Nat Iasi 109(1):62-65

28. Malawski SK, Lukawski S (1991) Pyogenic infection of the spine. Clin Orthop Relat Res 272:58-66

29. Martin V, Pfeiffer DU, Zhou X, Xiao X, Prosser DJ, Guo F, Gilbert M (2011) Spatial distribution and risk factors of highly pathogenic avian influenza (HPAI) H5N1 in China. PLoS Pathog 7(3):e1001308 (Epub 2011 Mar 3)

30. Nasef N, O'Brien K, Wylie L, Unger S (2010) Lessons from SARS: a retrospective study of outpatient care during an infectious disease outbreak. BMC Pediatr 10:51

31. Nassar IM, de la Llana R, Garrido P, Martinez-Sanz R (2005) Mitro-aortic infective endocarditis produced by Erysipelothrix rhusiopathiae: case report and review of the literature. J Heart Valve Dis 14(3):320-324

32. Neumann G, Kawaoka Y (2011) The first influenza pandemic of the new millennium. Influenza Other Respir Viruses 5(3):157-166. doi:10.1111/j.1750-2659.2011.00231.x (Epub 2011 Feb 28. Review)

33. Puopolo M, Ladogana A, Vetrugno V, Pocchiari M (2011) Transmission of sporadic Creutzfeldt-Jakob disease by blood transfusion: risk factor or possible biases. Transfusion 51(7):1556-1566 (Epub 2011 Jan 7)

34. Reboli AC, Farrar WE (1989) Erysipelothrix rhusiopathiae: an occupational pathogen. Clin Microbiol Rev 2 (4):354-359

35. Rocha MP, Fontoura PR, Azevedo SN, Fontoura AM (1989) Erysipelothrix endocarditis with previous cutaneous lesion: report of a case and review of the literature. Rev Inst Med Trop Sao Paulo 31(4):286-289

36. Rodrigo T, Caylà J (2011) Working Group of the Network of Public Health Research Centres Euro Public health crises: the development of a consensus document on their management in Spain. Euro Surveill 16(15) (pii:19841)

37. Roll U, Yaari R, Katriel G, Barnea O, Stone L, Mendelson E, Mandelboim M, Huppert A (2011) Onset of a pandemic: characterizing the initial phase of the swine flu (H1N1) epidemic in Israel. BMC Infect Dis 11:92

38. Rowan KM, Harrison DA, Walsh TS, McAuley DF, Perkins GD, Taylor BL, Menon DK (2010) The Swine Flu Triage (SwiFT) study: development and ongoing refinement of a triage tool to provide regular information to guide immediate policy and practice for the use of critical care services during the H1N1 swine influenza pandemic. Health Technol Assess 14(55):335-492 (review)

39. Ryan R, Hill S, Lowe D, Allen K, Taylor M, Mead C (2011) Notification and support for people exposed to the risk of Creutzfeldt-Jakob disease (CJD) (or other prion diseases) through medical treatment (iatrogenically). Cochrane Database Syst Rev (3):CD007578 (review)

40. Scotch M, Brownstein JS, Vegso S, Galusha D, Rabinowitz P (2011) Human vs. animal outbreaks of the 2009 swine-origin H1N1 influenza A epidemic. Ecohealth (Epub ahead of print)

41. Spoljar S, Budimcić D, Lipozencić J, Ljubojević S (2006) Erysipeloid—case report. Acta Dermatovenerol Croat 14(2):90-93

42. Traer EA, Williams MR, Keenan JN (2008) Erysipelothrix rhusiopathiae infection of a total knee arthroplasty an occupational hazard. J Arthroplast 23(4):609-611

43. Tranulis MA, Benestad SL, Baron T, Kretzschmar H (2011) Atypical prion diseases in humans and animals. Top Curr Chem 305:23-50

44. Trevitt CR, Singh PN (2003) Variant Creutzfeldt-Jakob disease: pathology, epidemiology, and public health implication. Am J Clin Nutr 78(3 Suppl):651S-656S

45. Yamamoto Y, Shioshita K, Takazono T, Seki M, Izumikawa K, Kakeya H, Yanagihara K, Tashiro T, Otsuka Y, Ohkusu K, Kohno S (2008) An autopsy case of Erysipelothrix rhusiopathiae endocarditis. Intern Med 47(15):1437-1440

46. Panagiotis VG, Anastasia TC (2003) Septic arthritis caused by Erysipelothrix rhusiopathiae infection after artroscopically assisted anterior cruciate ligament reconstruction Arthroscopy. J Arthrosc Relat Surg 19(3):26

47. Van Kerkhove MD, Mumford E, Mounts AW, Bresee J, Ly S, Bridges CB, Otte J (2011) Highly pathogenic avian influenza (H5N1): pathways of exposure at the animal-human interface, a systematic review. PLoS One 6(1):e14582 (review). Erratum in: PLoS One, 2012 7(1)

48. Veraldi S, Girgenti V, Dassoni F, Gianotti R (2009) Erysipeloid: a review. Clin Exp Dermatol 34(8):859-862

49. Wang Q, Chang BJ, Riley TV (2009) Erysipelothrix rhusiopathiae. Microbiol (Epub ahead of print) 